\title{
ANALISIS WILLINGNESS TO PAY MASYARAKAT TERHADAP PENINGKATAN PELAYANAN PDAM DI JALAN DANAU SENTARUM DAN SEKITARNYA
}

\author{
Suprihatiningsih Lestari ${ }^{1}$, Endang Mulyani ${ }^{2}$, Kartini $^{2}$ \\ ${ }^{1}$ Program Studi Teknik Lingkungan, Fakultas Teknik, Universitas Tanjungpura, Pontianak \\ ${ }^{2}$ Program Studi Teknik Sipil, Fakultas Teknik, Universitas Tanjungpura, Pontianak \\ Email : iiey.taprilmop91@yahoo.co.id
}

\begin{abstract}
ABSTRAK
Air merupakan faktor penting dalam pemenuhan kebutuhan vital bagi mahluk hidup diantaranya sebagai air minum atau keperluan rumah tangga lainnya. Air yang digunakan harus bebas dari kuman penyakit dan tidak mengandung bahan beracun. Berkaitan dengan hal tersebut, dengan adanya sarana dan prasarana air bersih serta ditunjang perencanaan yang baik diharapkan dapat membantu masyarakat dalam memenuhi akan kebutuhan air bersih, karena kebutuhan manusia akan air sangat kompleks antara lain untuk minum, masak, mandi, mencuci (bermacam-macam cucian) dan sebagainya. Pelayanan pendistribusian air di Kota Potianak tidak semua jalur pendistribusian dapat menggunakan air dari PDAM ini dengan maksimal karena adanya kendala dalam pendistribusian air tersebut maka ada beberapa wilayah di Kota Pontianak yang mengalami permasalahan dalam pengaliran air bersih dari PDAM Kota Pontianak. Penelitian ini menggunakan metode CVM (Contingent Valuation Method) digunakan untuk mengestimasi biaya yang akan dikeluarkan masyarakat, dan metode regresi berganda digunakan untuk menganalisa faktor-faktor dominan yang mempengaruhi masyarakat dalam membayar iuran PDAM setiap bulannya. Pogram yang dapat membantu dalam penelitian ini yaitu Microsoft Excel 2007 dan SPSS versi 16. Hasil Penelitian yang dihasilkan yaitu besarnya estimasi nilai WTP (willingness To Pay) masyarakat terhadap peningkatan pelayanan PDAM di Jalan Danau Sentarum dan sekitarnya yaitu Rp 1.800,-. Sedangkan faktor-faktor dominan yang mempengaruhi kesediaan membayar masyarakat dalam membayar iuran air untuk peningkatan pelayanan PDAM di Jalan Danau Sentarum dan sekitarnya yaitu tingkat pendapatan, tingkat pengetahuan dan pengeluaran rata-rata rumah tangga.
\end{abstract}

Kata Kunci: WTP (willingness To Pay), PDAM Kota Pontianak

\begin{abstract}
Water is an important factor in fulfilling the vital needs for living organisms such as for drinking or other domestic purposes. water must be free from germs and does not contain of toxic materials. Related to that, the presence of water infrastructure and supported good planning are expected to assist the public to fulfilling the needs of clean water, because the human need for water is very complex, such as for drinking, cooking, bathing, washing (laundry variety) and so on. Water distribution services in Potianak cannot distribute all channels using water from the PDAM because there is problem in the water distribution then there are some areas in Pontianak are experiencing problems in distributing the water from PDAM Pontianak. This study uses the CVM (Contingent Valuation Method) that useful to estimate the costs people pay, and the multiple regression method was used to analyze the dominant factors affecting the public in paying dues to PDAM every month. Program that can assist in this research is a Microsoft Excel 2007 and SPSS version $16^{\text {th }}$. Results are amount of the estimated value of public WTP (willingness to pay) to increase PDAM service on Sentarum Lake Street Area is Rp 1.800, -. Meanwhile, dominant factors that influence the willingness people to pay the dues for water service improvement on Sentarum Lake Street Area are the level of income, level of knowledge, and the average expenditure of households.
\end{abstract}

Keywords: public WTP (willingness to pay), PDAM Pontianak. 


\section{Pendahuluan}

Kehidupan manusia termasuk lingkungan yang ada disekitarnya sangat dipengaruhi dan ditentukan oleh keberadaan air. Air oleh manusia, secara langsung dimanfaatkan untuk memenuhi kebutuhan hidup mereka sehari-hari seperti minum, mandi dan cuci, sedangkan pemanfaatannya yang (secara) tidak langsung adalah untuk mengembangkan lingkungan hidupnya. Disamping itu masih ada kemampuan air yang lain yang sering kali diabaikan, yakni "menggelontor?" atau melarutkan hampir semua limbah sejauh daya untuk hal tersebut masih ada. (Hanna Rambe, 1984 )

PDAM Kota Pontianak merupakan PDAM yang berada di Kota Pontianak, PDAM ini melayani pendistribusian air ke seluruh rumah-rumah masyarakat yang ada di Kota Pontianak terutama rumah masyarakat yang sudah ada jalur pendistribusian air dari PDAM. Pelayanan pendistribusian air di Kota Potianak tidak semua jalur pendistribusian dapat menggunakan air dari PDAM ini dengan maksimal karena adanya kendala dalam pendistribusian air tersebut maka ada beberapa wilayah di Kota Pontianak yang mengalami permasalahan dalam pengaliran air bersih dari PDAM Kota Pontianak. Permasalahan yang timbul dari pendistribusian air PDAM ke perumahan warga masyarakat dapat berupa air yang keruh, macetnya dalam pengaliran air ke rumah-rumah warga hingga pendistribusian air yang tidak berjalan sama sekali, tetapi tetap harus membayar iuran PDAM tiap bulannya. Di Jalan Danau Sentarum merupakan daerah yang selalu membayar iuran PDAM setiap bulannya walaupun terkadang warga masyarakat di komplek tersebut mengalami permasalahan dalam pendistribusian air dari PDAM ke rumah-rumah warga.

Permasalahan tersebut juga dialami oleh pelanggan PDAM yang berada di Jalan Danau Sentarum dan sekitarnya. Dimana Jalan Danau Sentarum terletak di Kelurahan Sungai Bangkong, Kecamatan Pontianak Kota, Kota Pontianak yang memiliki jumlah pelanggan PDAM 1.799 pelanggan yang terdiri dari pelanggan rumah tangga maupun pelanggan non rumah tangga. Dengan biaya pembayaran air per meter kubiknya untuk rumah tangga semi permanen yaitu Rp 1.600,-. Pelanggan PDAM tersebut hanya memiliki fasilitas berupa keran air, pipa distribusi dan juga pipa dinas ke meteran masing-masing rumah.

\section{Metodologi Penelitian}

a. Lokasi Penelitian

Penelitian ini akan diambil lokasi yang bertempat di wilayah Pontianak Kota khususnya di Jalan Danau Sentarum Komplek Sentarum Sejahtera II dan sekitarnya.

\section{b. Jenis Data}

Data-data yang diperlukan dalam penelitian ini adalah data primer dan data sekunder. Data primer dapat didapat dari hasil kuesioner yang akan dibagikan kepada masyarakat di Jalan Danau Sentarum Kompek Sentarum Sejahtera II. Data ini untuk mengetahui kesediaan membayar PDAM terhadap pelayanan PDAM yang sudah ada, serta untuk mendapatkan rekomendasi dari warga masyarakat terhadap pelayanan PDAM.

Data sekunder ini dapat diperoleh dari berbagai instansi pemerintah maupun swasta diantaranya yaitu Data jumlah penduduk, kepadatan penduduk serta peta dari kelurahan sei.bangkong ataupun dari kantor kecamatan Pontianak Kota. Tarif biaya pemakaian layanan air bersih dan jalur distribusi air dari PDAM Kota Pontianak. 


\section{c. Metode Pengambilan Sampel}

Metode yang digunakan yaitu metode stratified random sampling yakni teknik pengumpulan dengan cara memperhatikan strata (tingkatan) didalam populasi secara acak. Sedangkan jumlah sampel konsumen yang digunakan yaitu 100 sampel.

\section{d. Metode Analisis Data}

Data dan informasi yang diperoleh dalam penelitian ini akan dianalisis secara kualitatif dan kuantitatif. Pengolahan dan analisis data dilakukan dengan bentuan program Statitical Product and Service Solutions (SPSS). Analisis data yang akan digunakan yaitu analisis regresi linier sederhana dan berganda, pengujian asumsi klasik dan juga analisis reliabilitas.

1. Memperkirakan Nilai Rata-rata WTP

Nilai rata-rata yang akan dikeluarkan oleh responden yang bersedia membayar dapat dihitung dengan menggunakan rumus dibawah ini (Walpole, 1997):

$$
E W T P=\frac{\sum_{i=1}^{n} W i}{n}
$$

\section{Dengan :}

EWTP = Rata-rata nilai WTP konsumen

$\mathrm{Wi} \quad$ = besar WTP yang bersedia dibayarkan

$\mathrm{i} \quad=$ responden yang bersedia membayar

$\mathrm{n} \quad=$ jumlah responden

2. Menjumlahkan Data

Setelah menduga nilai tengah WTP maka selanjutnya diduga nilai total WTP dari responden dengan menggunakan rumus:

$$
T W T P=\sum_{i=1}^{n} W T P_{i}\left(\frac{n_{i}}{N}\right) P
$$

dimana :

$\Sigma T W T P \quad=$ Total WTP

WTPi $\quad=$ WTP individu sampel ke-i

ni = Jumlah sampel ke-i yang bersedia membayar sebesar WTP

$N \quad=$ Jumlah sampel

$P \quad=\quad$ Jumlah populasi per 3 tahun terakhir

$i \quad=$ Responden ke- $i$ yang bersedia membayar $(i=1,2, . ., \mathrm{n})$

\section{Hasil dan Pembahasan}

a. Karakteristik Responden

Responden dalam penelitian ini adalah pelanggan PDAM Kota Pontianak yang berada di Jalan Danau Sentarum Komplek Cendana Asri, komplek Sentarum Sejahtera II, Gang Mufakat dan juga Komplek Green Silva. Jumlah responden dalam penelitian ini yaitu berjumlah 100 orang. Karakteristik responden pelanggan PDAM Kota Ponttianak ini terdiri dari beberapa aspek yaitu: jenis kelamin, usia, pendidikan, pekerjaan, pendapatan, luas pekarangan, besarnya uang yang selama ini dikeluarkan untuk membayar iuran PDAM, status pernikahan, jenis pekerjaan, pengetahuan mengenai kualitas air bersih dan juga fasilitas dari PDAM untuk memenuhi kebutuhan air sehari-hari. 
Tabel 1. Karakteristik Responden Berdasarkan Jenis Kelamin dan Usia

\begin{tabular}{|c|c|c|c|c|c|c|c|c|}
\hline & & & \multicolumn{5}{|c|}{ Usia } & \multirow[b]{2}{*}{ Total } \\
\hline & & & $\begin{array}{c}21 \text { tahun - } 30 \\
\text { tahun }\end{array}$ & $\begin{array}{c}31 \text { tahun - } 40 \\
\text { tahun }\end{array}$ & $\begin{array}{c}41 \text { tahun - } 50 \\
\text { tahun }\end{array}$ & $\begin{array}{c}51 \text { tahun - } 60 \\
\text { tahun }\end{array}$ & $\begin{array}{c}61 \text { tahun - } 70 \\
\text { tahun }\end{array}$ & \\
\hline \multirow[t]{4}{*}{ JenisKelamin } & Pria & Count & 15 & 17 & 28 & 16 & 8 & 84 \\
\hline & & $\%$ of Total & $15.0 \%$ & $17.0 \%$ & $28.0 \%$ & $16.0 \%$ & $8.0 \%$ & $84.0 \%$ \\
\hline & Wanita & Count & 1 & 5 & 7 & 2 & 1 & 16 \\
\hline & & $\%$ of Total & $1.0 \%$ & $5.0 \%$ & $7.0 \%$ & $2.0 \%$ & $1.0 \%$ & $16.0 \%$ \\
\hline \multirow[t]{2}{*}{ Total } & & Count & 16 & 22 & 35 & 18 & 9 & 100 \\
\hline & & $\%$ of Total & $16.0 \%$ & $22.0 \%$ & $35.0 \%$ & $18.0 \%$ & $9.0 \%$ & $100.0 \%$ \\
\hline
\end{tabular}

Sumber: Olahan Data Kuesioner, 2014

Dapat dilihat dari tabel bahwa dari 100 responden yang diteliti, terdapat sebanyak $84 \%$ responden berjenis kelamin pria, sedangkan sisanya yaitu sebesar $16 \%$ adalah responden wanita. Berdasarkan pengamatan secara langsung, pelanggan PDAM lebih banyak pria daripada wanita. Hal ini dikarenakan, pria merupakan kepala keluarga, sehingga yang menjadi pelanggan PDAM lebih banyak pria daripada wanita.

Pada tabel dapat dilihat bahwa tingkat usia reponden tergolong cukup bervariasi dengan distribusi usia 21 tahun sampai 70 tahun. Tingkat usia menjelaskan bahwa, pelanggan PDAM Kota Pontianak cukup banyak, dari usia muda hingga tua. Tingkat usia seseorang mencerminkan tingkat kedewasaan orang tersebut dalam mengambil keputusan atau tindakan mengenai hal-hal yang berhubungan dengan dirinya. Berikut ini adalah rekapitulasi responden berdasarkan usia menurut Depkes RI (2009):

Tabel 2. Karakteristik Responden Berdasarkan Usia menurut Depkes RI (2009)

\begin{tabular}{|c|c|c|c|c|}
\hline No & Usia & Kategori Umur & Jumlah & Persentase (\%) \\
\hline 1 & $0-5$ tahun & Masa Balita & 0 & 0 \\
\hline 2 & $5-11$ tahun & Masa Kanak-kanak & 0 & 0 \\
\hline 3 & $12-16$ tahun & Masa Remaja Awal & 0 & 0 \\
\hline 4 & $17-25$ tahun & Masa Remaja Akhir & 5 & 5 \\
\hline 5 & $26-35$ tahun & Masa Dewasa Awal & 19 & 19 \\
\hline 6 & $36-45$ tahun & Masa Dewasa Akhir & 31 & 31 \\
\hline 7 & $46-55$ tahun & Masa Lansia Awal & 32 & 32 \\
\hline 8 & $56-65$ tahun & Masa Lansia Akhir & 12 & 12 \\
\hline 9 & $\geq 66$ tahun & Masa Manula & 1 & 1 \\
\hline \multicolumn{3}{|c|}{ Jumah } & 100 & 100 \\
\hline
\end{tabular}

Sumber: Olahan Data Kuesioner, 2014

Jumlah responden tertinggi terdapat pada kategori umur masa lansia awal yaitu pada usia 46 - 55 tahun yang berjumlah 32 orang (32\%) disusul pada kategori umur masa dewasa akhir yaitu pada usia 36 - 45 tahun, yaitu berjumlah 31 orang (31\%), kemudian pada kategori umur masa dewasa awal yaitu pada usia 26 - 35 tahun berjumlah 19 orang (19\%), kemudian disusul dengan kategori masa lansia akhir pada usia $56-65$ tahun berjumlah 12 orang (12\%) sedangkan pada kategori masa remaja awal pada rentang usia $17-25$ tahun berjumlah 5 orang $(5 \%)$ dan yang terakhir yaitu pada kategori usia masa manula dengan usia $\geq 66$ tahun berjumlah 1 orang (1\%).

Status pernikahan dapat mempengaruhi banyaknya debit air yang dgunakan dalam sehari-hari. Hal ini disebabkan oleh, penggunaan air oleh responden yang belum menikah lebih sedikit dibandingkan dengan responden yang sudah menikah karena responden yang sudah menikah memiliki jumlah anggota keluarga yang lebih banyak daripada responden yang belum menikah.Berikut ini adalah rekapitulasi data 100 responden berdasarkan status pernikahan dan jumlah anggota keluarga: 
Tabel 3. Karakteristik Responden Berdasarkan Status Pernikahan dan Jumlah Anggota Keluarga

\begin{tabular}{|c|c|c|c|c|c|c|c|c|}
\hline & \multicolumn{5}{|c|}{ JumlahAnggotaKeluarga } & \multirow[b]{2}{*}{ Total } \\
\hline & & & $\leqslant 2$ orang & 3 orang & 4 orang & 5 orang & $>6$ orang & \\
\hline \multirow[t]{4}{*}{ Status } & Belum Menikah & Count & 6 & 2 & 1 & 1 & 0 & 10 \\
\hline & & $\%$ of Total & $6.0 \%$ & $2.0 \%$ & $1.0 \%$ & $1.0 \%$ & $.0 \%$ & $10.0 \%$ \\
\hline & Menikah & Count & 5 & 23 & 31 & 23 & 8 & 90 \\
\hline & & $\%$ of Total & $5.0 \%$ & $23.0 \%$ & $31.0 \%$ & $23.0 \%$ & $8.0 \%$ & $90.0 \%$ \\
\hline \multirow[t]{2}{*}{ Total } & & Count & 11 & 25 & 32 & 24 & 8 & 100 \\
\hline & & $\%$ of Total & $11.0 \%$ & $25.0 \%$ & $32.0 \%$ & $24.0 \%$ & $8.0 \%$ & $100.0 \%$ \\
\hline
\end{tabular}

Sumber: Olahan Data Kuesioner, 2014

Dari tabel 3 diatas, dapat dilihat bahwa hanya 10 orang $(10 \%)$ responden dengan status belum menikah dan sebanyak 90 orang $(90 \%)$ responden sudah menikah. Hal ini menunjukkan bahwa pelanggan PDAM kebanyakan sudah menikah. Dari tabel 3 diatas dapat dilihat juga bahwa jumlah anggota keluarga yang paling tinggi yaitu pada jumlah 4 orang sebesar 32 orang (32\%), kemudian dengan jumlah tanggungan 3 orang sebesar 25 orang (25\%), dengan jumlah tanggungan 5orang sebesar 24 orang (24\%), dengan jumlah tanggungan $\leq 2$ orang sebesar 11 orang (11\%) dan yang terakhir dengan jumlah anggota keluarga $\geq 6$ orang sebesar 8 orang (8\%). Jumlah anggota keluarga juga dapat mempengaruhi dari jumlah penggunaan air setiap bulannya sehingga mempengaruhi pengeluaran rata-rata pelanggan rumah tangga.

Tingkat pendidikan yang lebih tinggi berpengaruh terhadap pemahaman seseorang terhadap peningkatan pelayanan PDAM serta kualitas air yang didapatkan dari pelayanan PDAM tersebut. Selain itu, tingkat pendidikan juga akan mempengaruhi jenis pekerjaan responden tersebut kemudian akan mempengaruhi tingkat pendapatan dan akan menentukan pengeluaran responden dalam mengkonsumsi air PDAM. Berikut ini adalah rekapitulasi data 100 responden berdasarkan pendidikan terakhir:

Tabel 4. Karakteristik Responden Berdasarkan Pendidikan Terakhir dan Pekerjaan

\begin{tabular}{|c|c|c|c|c|c|c|c|c|}
\hline & & & \multicolumn{5}{|c|}{ Pekerjaan } & \multirow[b]{2}{*}{ Total } \\
\hline & & & $\begin{array}{l}\text { Pelajar atau } \\
\text { mahasiswa }\end{array}$ & $\begin{array}{c}\text { Pegawai } \\
\text { Swasta }\end{array}$ & $\begin{array}{c}\text { Pegawai } \\
\text { Negeri }\end{array}$ & Wiraswasta & Pensiunan & \\
\hline \multirow[t]{6}{*}{ Pendidikan } & SMU & Count & 1 & 13 & 10 & 9 & 9 & 42 \\
\hline & & $\%$ of Total & $1.0 \%$ & $13.0 \%$ & $10.0 \%$ & $9.0 \%$ & $9.0 \%$ & $42.0 \%$ \\
\hline & Sarjana & Count & 0 & 20 & 27 & 5 & 3 & 55 \\
\hline & & $\%$ of Total & $.0 \%$ & $20.0 \%$ & $27.0 \%$ & $5.0 \%$ & $3.0 \%$ & $55.0 \%$ \\
\hline & Diploma & Count & 0 & 1 & 0 & 1 & 1 & 3 \\
\hline & & $\%$ of Total & $.0 \%$ & $1.0 \%$ & $.0 \%$ & $1.0 \%$ & $1.0 \%$ & $3.0 \%$ \\
\hline \multirow[t]{2}{*}{ Total } & & Count & 1 & 34 & 37 & 15 & 13 & 100 \\
\hline & & $\%$ of Total & $1.0 \%$ & $34.0 \%$ & $37.0 \%$ & $15.0 \%$ & $13.0 \%$ & $100.0 \%$ \\
\hline
\end{tabular}

Sumber: Olahan Data Kuesioner, 2014

Dari tabel 4 tersebut, maka dapat dilihat pendidikan responden mayoritas terdapat pada sarjana yaitu sebanyak 55 orang dengan pekerjaan pegawai negeri yaitu sebanyak 27 orang (27\%) disusul dengan pekerjaan Pegawai Swasta sebanyak 20 orang $(20 \%)$ kemudian dengan pekerjaan sebagai wiraswasta sebanyak 5 orang $(5 \%)$ dan pekerjaan pensiunan sebanyak 3 orang (3\%). Pendidikan terakhir responden SMU ada 42 orang dengan jenis pekerjaan dominan pada pegawai swasta 13 orang (13\%) kemudian dengan pekerjaan pegawai negeri sebanyak 10 orang $(10 \%)$ disusul dengan pekerjaan wiraswasta dan pensiunan sebanyak 9 orang (9\%) dan terakhir 1 orang (1\%) responden tercatat sebagai pelajar atau mahasiswa. Pendidikan terakhir sebagai Diploma yaitu hanya 3 orang (3\%) dengan bekerja sebagai pegawai swasta, wiraswasta dan pensiunan masing-masing yaitu 1 orang (1\%). Hal ini berhubungan juga dengan ketidaktahuan responden terhadap kualitas air PDAM dan juga tingkat pendapatan responden. Karena semakin tinggi tingkat pendidikan responden, maka semakin tinggi pula tingkat 
pengetahuannya terhadap kualitas air bersih. Begitu juga terhadap pekerjaan dan pendapatan, semakin tinggi tingkat pendidikan maka pekerjaan dan pendapatan juga dapat meningkat.

Tingkat pendapatan responden di Jalan Danau Sentarum bervariasi. Hal ini akan mempengaruhi pengeluaran responden setiap bulannya. Berikut adalah rekapitulasi data 100 responden berdasarkan tingkat pendapatan dan pengeluaran:

Tabel 5. Karakteristik Responden Berdasarkan Pendapatan

\begin{tabular}{|c|c|c|c|c|c|c|c|c|}
\hline & & & \multicolumn{5}{|c|}{ Pengeluaran } & \multirow[b]{2}{*}{ Total } \\
\hline & & & $<500$ ribu & $\begin{array}{c}500 \text { ribu - } \\
\text { 1juta 500ribu }\end{array}$ & $\begin{array}{c}\text { 1juta 500ribu } \\
\text { - 2juta } \\
\text { 500ribu }\end{array}$ & $\begin{array}{c}\text { 2juta 500ribu } \\
\text { - 3juta } \\
\text { 500ribu }\end{array}$ & $\begin{array}{l}=3 \text { juta } \\
\text { 500ribu }\end{array}$ & \\
\hline \multirow[t]{10}{*}{ Pendapatan } & $\& 1$ juta & Count & 2 & 1 & 0 & 0 & 0 & 3 \\
\hline & & $\%$ of Total & $2.0 \%$ & $1.0 \%$ & $.0 \%$ & $.0 \%$ & $.0 \%$ & $3.0 \%$ \\
\hline & 1 juta - 2 juta & Count & 3 & 4 & 0 & 0 & 0 & 7 \\
\hline & & $\%$ of Total & $3.0 \%$ & $4.0 \%$ & $.0 \%$ & $.0 \%$ & $.0 \%$ & $7.0 \%$ \\
\hline & 2 juta - 3 juta & Count & 0 & 15 & 13 & 2 & 0 & 30 \\
\hline & & $\%$ of Total & $.0 \%$ & $15.0 \%$ & $13.0 \%$ & $2.0 \%$ & $.0 \%$ & $30.0 \%$ \\
\hline & 3 juta - 4 juta & Count & 0 & 1 & 20 & 18 & 0 & 39 \\
\hline & & $\%$ of Total & $.0 \%$ & $1.0 \%$ & $20.0 \%$ & $18.0 \%$ & $.0 \%$ & $39.0 \%$ \\
\hline & $>4$ juta & Count & 0 & 0 & 1 & 10 & 10 & 21 \\
\hline & & $\%$ of Total & $.0 \%$ & $.0 \%$ & $1.0 \%$ & $10.0 \%$ & $10.0 \%$ & $21.0 \%$ \\
\hline \multirow[t]{2}{*}{ Total } & & Count & 5 & 21 & 34 & 30 & 10 & 100 \\
\hline & & $\%$ of Total & $5.0 \%$ & $21.0 \%$ & $34.0 \%$ & $30.0 \%$ & $10.0 \%$ & $100.0 \%$ \\
\hline
\end{tabular}

Sumber: Olahan Data Primer, 2014

Dari tabel 5 diatas dapat dilihat bahwa sebanyak 39 orang (39\%) responden berpendapatan yang berkisar antara Rp. 3.000.001 - Rp. 4.000.000 dengan pengeluaran Rp 500.000 - Rp 1.500 .000 sebanyak 1 orang (1\%) dengan pengeluaran $R p 1.500 .000-R p$ 2.500 .000 sebanyak 20 orang (20\%) dengan pengeluaran $\mathrm{Rp} 2.500 .000$ - Rp 3.500 .000 sebanyak 18 orang (18\%). Kemudian sebanyak 30 orang (30\%) responden berpendapat yang berkisar antara Rp.2.000.001 - Rp. 3.000 .000 dengan pengeluaran Rp Rp 500.000 - Rp 1.500 .000 sebanyak 15 orang (15\%) dengan pengeluaran Rp 1.500 .000 - Rp 2.500 .000 sebanyak 13 orang (13\%) dengan pengeluaran Rp 2.500 .000 - Rp 3.500 .000 sebanyak 2 orang (2\%). Kemudian Sebanyak 21 orang (21\%) berpendapatan $\geq$ Rp.4.000.001 dengan pengeluaran Rp 1.500.000 - Rp 2.500.000 sebanyak 1 orang (1\%) dengan pengeluaran Rp $2.500 .000-R p$ 3.500 .000 sebanyak 10 orang (10\%) dan dengan pengeluaran $\geq \mathrm{Rp} 3.500 .000$ sebanyak 10 orang (10\%). Lalu 7 orang (7\%) berpendapatan diantara Rp. $1.000 .001-$ rp.2.000.000 dengan pengeluaran $\leq 500.000$ sebanyak 3 orang (3\%) dengan pengeluaran Rp 500.000 - Rp 1.500.000 sebanyak 4 orang (4\%). Dan yang terakhir ada 3 orang (3\%) yang berpendapatan $\leq$ Rp.1.000.000,- dengan pengeluaran $\leq 500.000$ sebanyak 2 orang (2\%) dengan pengeluaran Rp 500.000 - Rp 1.500 .000 sebanyak 1 orang (1\%). Hal ini membuktikan bahwa pelanggan PDAM Kota Pontianak bervariasi juga dari segi ekonominya.

Pengetahuan responden tentang kualitas air bersih ditentukan oleh pola fikir dan pengetahuannya mengenai kualitas air tersebut. Hal ini akan berkaitan dengan keinginan masyarakat dalam membayar iuran PDAM setiap bulannya Berikut ini rekapitulasi data 100 responden berdasarkan tingkat pengetahuan kualitas air dan kesediaan masyarakat dalam membayar iuran PDAM setiap bulannya: 
Tabel 6. Karakteristik Responden Berdasarkan Tingkat Pengetahuan dan Kesediaan Dalam Membayar

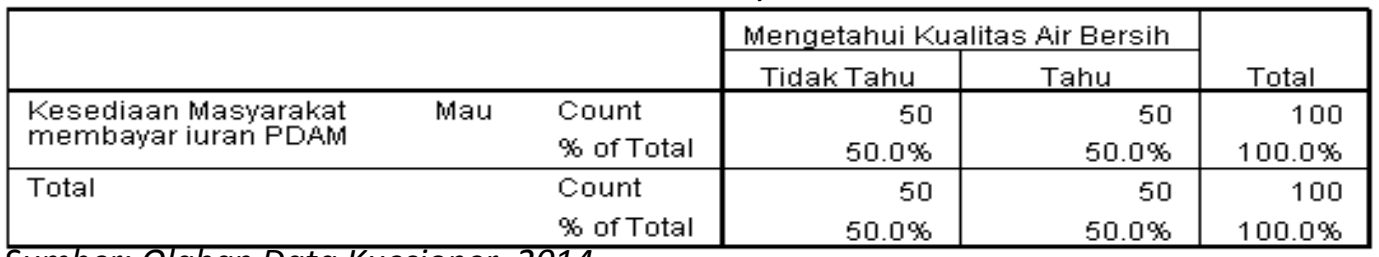

Sumber: Olahan Data Kuesioner, 2014

Dari tabel 6 diatas dapat dilihat bahwa 100 orang (100\%) responden bersedian dala membayar iuran PDAM dan 50 orang (50\%) responden tahu mengenai kualitas air bersih dan 50 orang $(50 \%)$ lagi tidak mengetahui tingkat mengetahui dengan kualitas air bersih. Kualitas air bersih PDAM yang dimaksud adalah air yang bersih secara fisik. Parameter fisik meliputi padatan terlarut, kekeruhan, warna, rasa, bau dan suhu. Keluhan dari masyarakat mengenai kualitas air bersih yaitu sering terjadinya kekeruhan. Sehingga bila terjadi kekeruhan yang tinggi pada air PDAM, ada yang dari responden masih mengolah air yang kurang bersih menjadi air yang lebih bersih dan jernih lagi. Pengolahan yang sering dilakukan yaitu dengan cara menambahkan tawas ataupun PAC kedalam bak mandi ataupun bak penampungan dari air PDAM setelah itu dilakukan pengadukan dan didiamkan beberapa saat agar partikel suspended dapat terendapkan di dasar bak penampungan. Setelah itu, air tersebut baru dapat digunakan dalam kegiatan sehari-hari.

Lokasi dan Luas Pekarangan yang dimiliki oleh responden dapat dilihat dari rekapitulasi data 100 responden berikut:

Tabel 7. Karakteristik responden Berdasarkan Lokasi dan Luas Pekarang

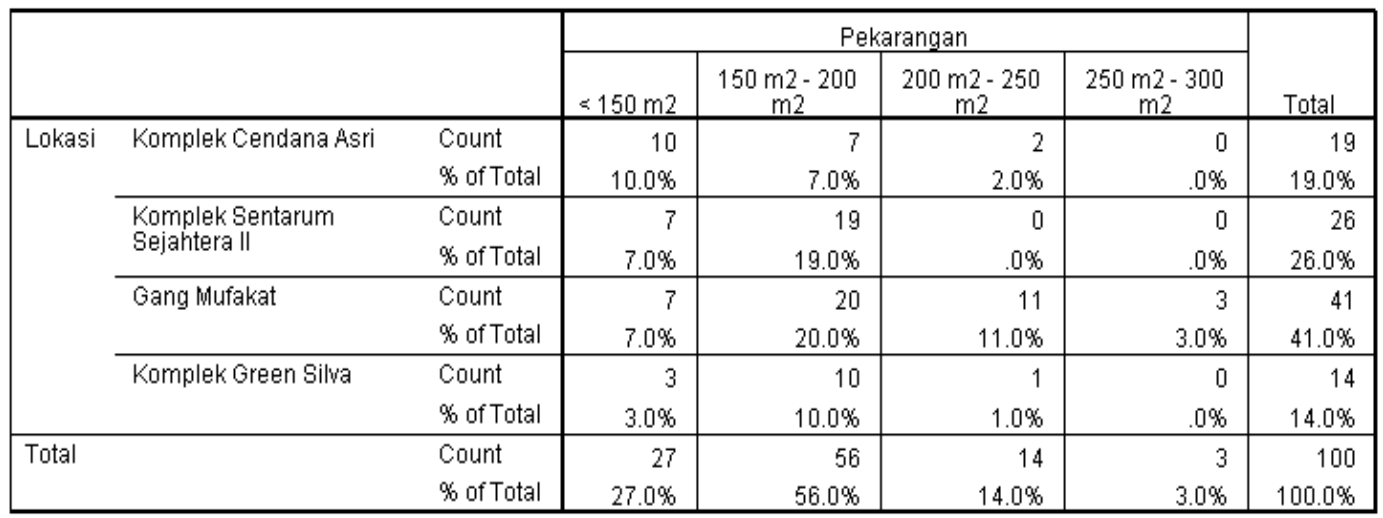

Sumber: Olahan Data Kuesioner, 2014

Dari tabel 7 diatas dapat dilihat responden yang berlokasi di Komplek Cendana Asri 19 orang $(19 \%)$ dengan luas pekarangan $\leq 150 \mathrm{~m}^{2}$ sebanyak 10 orang $(10 \%)$. Dengan luas Pekarangan $150 \mathrm{~m}^{2}-200 \mathrm{~m}^{2}$ sebanyak 7 orang (2\%). Dengan luas pekarangan $200 \mathrm{~m}^{2}-250 \mathrm{~m}^{2}$ sebanyak 2 orang (2\%). Kemudian responden yang berlokasi di Komplek Sentarum Sejahtera II sebanyak 26 orang (26\%) dengan luas pekarangan $\leq 150 \mathrm{~m}^{2}$ sebanyak 7 orang (7\%) dengan luas pekarangan $150 \mathrm{~m}^{2}-200 \mathrm{~m}^{2}$ sebanyak 19 orang (19\%). Lalu responden yang berlokasi di Gang Mufakat sebanyak 41 Orang (41\%) dengan luas pekarangan $\leq 150 \mathrm{~m}^{2}$ sebanyak 7 orang (7\%) dengan luas pekarangan $150 \mathrm{~m}^{2}-200 \mathrm{~m}^{2}$ sebanyak 20 orang $(20 \%)$ dengan luas pekarangan $200 \mathrm{~m}^{2}-250 \mathrm{~m}^{2}$ sebanyak 11 orang (11\%) dan dengan luas pekarangan $250 \mathrm{~m}^{2}-$ $300 \mathrm{~m}^{2}$ sebanyak 3 orang (3\%). Dan responden yang berlokasi di Komplek Green Silva sebanyak 14 orang $(14 \%)$ dengan luas pekarangan $\leq 150 \mathrm{~m}^{2}$ sebanyak 3 orang $(3 \%)$ dengan luas pekarangan $150 \mathrm{~m}^{2}-200 \mathrm{~m}^{2}$ sebanyak 10 orang (10\%) dengan luas pekarangan $200 \mathrm{~m}^{2}-250$ $\mathrm{m}^{2}$ sebanyak 1 orang (1\%). Hal ini menunjukkan bahwa luas tanah dan luas bangunan konsumen bervariasi, sehingga mempengaruhi juga jumlah kebutuhan air yang digunakan sehari-hari seperti menyiram tanaman di taman ataupun dalam membersihkan rumah. 
b. $\quad$ Mengestimasi Besarnya Nilai WTP (Willingness To Pay)

Dari 100 responden yang diwawancara secara mendalam dengan menggunakan kuisioner maka didapat kelompok pengguna dikaitkan dengan kelompok WTP sebagai berikut:

Tabel 8. Kelompok Pengguna Dikaitkan Dengan Kelompok WTP

\begin{tabular}{|c|c|c|c|c|c|c|c|}
\hline & & & \multicolumn{4}{|c|}{ Kelompok WTP } & \multirow[b]{2}{*}{ Total } \\
\hline & & & $\mathrm{Rp}_{1.000-\mathrm{Rp}}$ & $\begin{array}{c}\mathrm{Rp} 1.600-\mathrm{Rp} \\
2.000\end{array}$ & $\begin{array}{c}\mathrm{Rp} 2.100-\mathrm{Rp} \\
2.500\end{array}$ & $\begin{array}{c}\mathrm{Rp} 2.600-\mathrm{Rp} \\
3.000\end{array}$ & \\
\hline \multirow[t]{8}{*}{ Kelompok Pengguna } & \multirow{2}{*}{$\begin{array}{l}\text { Pendapatan Sangat } \\
\text { Tinggi }\end{array}$} & Count & 6 & 17 & 6 & 3 & 32 \\
\hline & & $\%$ of Total & $6.0 \%$ & $17.0 \%$ & $6.0 \%$ & $3.0 \%$ & $32.0 \%$ \\
\hline & \multirow[t]{2}{*}{ Pendapatan Tinggi } & Count & 10 & 14 & 4 & 1 & 29 \\
\hline & & $\%$ of Total & $10.0 \%$ & $14.0 \%$ & $4.0 \%$ & $1.0 \%$ & $29.0 \%$ \\
\hline & \multirow[t]{2}{*}{ Pendapatan Sedang } & Count & 11 & 11 & 3 & 1 & 26 \\
\hline & & $\%$ of Total & $11.0 \%$ & $11.0 \%$ & $3.0 \%$ & $1.0 \%$ & $26.0 \%$ \\
\hline & \multirow[t]{2}{*}{ Pendapaatan Rendah } & Count & 8 & 4 & 1 & 0 & 13 \\
\hline & & $\%$ of Total & $8.0 \%$ & $4.0 \%$ & $1.0 \%$ & $.0 \%$ & $13.0 \%$ \\
\hline \multirow{2}{*}{\multicolumn{2}{|c|}{ Total }} & Count & 35 & 46 & 14 & 5 & 100 \\
\hline & & $\%$ of Total & $35.0 \%$ & $46.0 \%$ & $14.0 \%$ & $5.0 \%$ & $100.0 \%$ \\
\hline
\end{tabular}

Sumber: Olahan Data Kuesioner, 2014

Dari tabel 8 diatas maka dapat dilihat bahwa kelompok pengguna paling banyak terdapat pada kelompok pengguna pendapatan sangat tinggi dengan jumlah 32 orang (32\%). Kemudian dengan pendapatan tinggi sebanyak 29 orang (29\%), dengan pendapatan sedang sebanyak 26 orang (26\%) dan dengan pendapatan rendah sebanyak 13 orang (13\%). Dari tabel 8 dapat dilihat pula bahwa kelompok WTP paling banyak terdapat pada Rp $1.600-\mathrm{Rp} 2.000$ per $\mathrm{m}^{3}$ sebanyak 46 orang (46\%). Artinya bahwa dari 100 responden, ada 46 orang (46\%) yang mengungkapkan kesediaan atau kemauan membayar (WTP) PDAM Kota Pontianak sebagai respon atas pelayanan pasokan air bersih PDAM setiap bulannya antara Rp $1.600-\mathrm{Rp} 2.000$ per $\mathrm{m}^{3}$. Sebanyak 35 orang (35\%) menyatakan bersedia membayar pada biaya antara $\mathrm{Rp} 1.000$ - Rp 1.500 per $\mathrm{m}^{3}$, artinya dari 100 responden ada 35 orang (35\%) mengungkapkan kesediaan atau kemauan membayar (WTP) sebagai respon atas pelayanan pasokan air bersih PDAM setiap bulannya antara $\mathrm{Rp} 1.000-\mathrm{Rp} 1.500$ per $\mathrm{m}^{3}$. Selanjutnya ada 14 orang (14\%) menyatakan bersedia membayar pada biaya antara $\mathrm{Rp} 2.100-\mathrm{Rp} 2.500$ per $\mathrm{m}^{3}$, artinya dari 100 responden ada 14 orang (14\%) mengungkapkan kesediaan atau kemauan membayar (WTP) sebagai respon atas pelayanan pasokan air bersih PDAM setiap bulannya antara Rp $2.100-\mathrm{Rp} 2.500$ per $\mathrm{m}^{3}$. Dan selanjutnya sebanyak 5 orang $(5 \%)$ yang menyatakan bersedia membayar pada biaya antara $\mathrm{Rp} 2.600$ - Rp 3.000 per $\mathrm{m}^{3}$ artinya dari 100 responden ada 5 orang (5\%) yang bersedia membayar (WTP) sebagai respon atas pelayanan pasokan air bersih PDAM setiap bulannya antara Rp $2.600-\mathrm{Rp} 3.000$ per $\mathrm{m}^{3}$. WTP rata-rata dari penelitian ini yaitu sebesar Rp 1.791 atau sebesar $\mathrm{Rp} 1800 / \mathrm{m}^{3}$. Hal ini menunjukkan bahwa nilai WTP dari

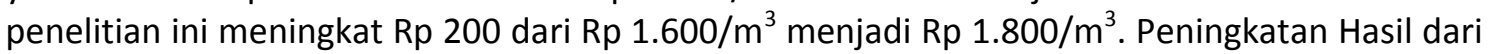
penelitian ini akan dijadikan sebagai saran atau masukan kepada pihak PDAM Kota Pontianak sebagai masukan harga retribusi iuran PDAM setiap bulannya per $\mathrm{m}^{3}$ untuk pengguna air golongan rumah tangga semi permanen untuk pemakaian air $>0-10 \mathrm{~m}^{3}$.

c. Analisis Faktor-faktor Kesediaan Membayar Konsumen Dalam Peningkatan Pelayanan PDAM

Estimasi terhadap faktor-faktor yang mempengaruhi kesediaan masyarakat membayar (Willingness to pay, WTP) terhadap peningkatan pelayanan PDAM Kota Pontianak dengan menggunakan analisis regresi berganda sebagai berikut: 
Tabel 9. Hasil Analisis Kesediaan Masyarakat dalam membayar iuran air PDAM dalam upaya peningkatan pelayanan PDAM

\begin{tabular}{|l|c|c|c|}
\hline \multicolumn{1}{|c|}{ Variabel } & Koefisien & Sig & Keterangan \\
\hline Constant & 7,411 & 0,000 & - \\
\hline JK & 0,070 & 0,430 & $(+)$ \\
\hline USIA & $-0,183$ & 0,070 & $(-)$ \\
\hline STTS & 0,106 & 0,389 & $(+)$ \\
\hline PNDDKN & $-0,106$ & 0,507 & $(-)$ \\
\hline PNDPTN & 0,255 & 0,001 & $(+)$ \\
\hline PKRG & 0,059 & 0,354 & $(+)$ \\
\hline PNGTHUAN & 0,187 & 0,004 & $(+)$ \\
\hline BIAYA & 0,185 & 0,010 & $(+)$ \\
\hline$R^{2}$ & $37,2 \%$ & & \\
\hline F- statistic & 6,747 & 0,000 & \\
\hline N & 100 & & \\
\hline
\end{tabular}

Sumber: Hasil Olahan Data Primer, 2014

Dari hasil analisis regresi berganda, fungsi WTP yang diperoleh adalah sebagai berikut:

WTP = 7,411 + 0,070 JK - 0,183 USIA + 0,106 STTS - 0,106 PNDDKN + 0,255 PNDPTN + 0,059 PKRG + 0,187 PNGTHUAN + 0,185 BIAYA

Nilai koefisien determinasi $\left(R^{2}\right)$ dari model regresi adalah $37,2 \%$. Hal ini menunjukkan bahwa variasi dari kemauan atau keinginan membayar (Willingness to pay,WTP) pelanggan PDAM dapat dijelaskan oleh variabel bebasnya ( jenis kelamin, usia, status pernikahan, pendidikan, pendapatan, luas pekarangan, tingkat pengetahuan dan biaya pengeluaran ratarata pelanggan rumah tangga) sebesar $37,2 \%$, sedangkan sisanya $62,8 \%$ diterangkan oleh variabel-variabel lainnya yang tidak terdapat pada model.

Nilai $F$ hitung sebesar 6,747 dengan tingkat signifikansi mendekati nol $(0,000)$. Mengingat nilai probabilitas signifikansi dari F-hitung adalah sangat kecil (jauh lebih kecil dari $0,05)$ maka variabel jenis kelamin, usia, status, pendidikan, pendapatan, luas pekarangan, tingkat pengetahuan dan biaya pengeluaran rata-rata pelanggan rumah tangga secara bersama-sama atau serentak terbukti secara signifikan berpengaruh terhadap variabel kesediaan masyarakat membayar (Willingness to pay,WTP) terhadap peningkatan pelayanan PDAM.

Secara individual variabel jenis kelamin, status pernikahan, tingkat pendapatan, luas pekarangan, tingkat pengetahuan dan biaya pengeluaran rata-rata pelanggan rumah tangga terbukti berpengaruh positif terhadap variabel kesediaan masyarakat membayar (willingness to pay, WTP) terhadap peningkatan pelayanan PDAM. Sedangkan variabel tingkat usia dan tingkat pendidikan berpengaruh negative terhadap variabel kesediaan masyarakat membayar (willingness to pay, WTP) terhadap peningkatan pelayanan PDAM. Dari tabel 5.21 dapat diketahui ada tiga dari delapan variabel independen yang diamati adalah signifikansi secara statistic dengan variabel kesediaan masyarakat membayar (willingness to pay, WTP) terhadap peningkatan pelayanan PDAM.

\section{d. Pembahasan}

Dari hasil penelitian yang telah dilakukan besarnya WTP yang dikeluarkan oleh 100 responden, dikaitkan dengan beberapa hipotesis yang dicantumkan pada bab sebelumnya, maka nilai WTP yang ditawarkan dari yang terkecil sampai nilai terbesar WTP yang ditawarkan responden diperoleh nilai rataan sebesar Rp 1.800/m3.

Sedangkan untuk faktor-faktor yang mempengaruhi besarnya nilai WTP berdasarkan dari hasil penelitian tesis Sri Winarna tahun 2003 dapat diketahui ada 4 dari 6 variabel bebas 
yang signifikan terhadap kesediaan atau kemauan dalam membayar PDAM di Kabupaten Karanganyar. Keempat variabel yang berpengaruh secara signifikan tersebut yaitu Pendapatan keluarga, pengeluaran rata-rata pelanggan rumah tangga, jumlah anggota keluarga dan tidak adanya sumber air lain. Sedangkan variabel yang tidak berpengaruh yaitu tingkat pendidikan dan luas pekarangan. Sedangkan bila dikaitkan dengan hasil penelitian dari Gusti Elfa Simanjuntak tahun 2009 dari 7 variabel bebas ada 2 variabel yang berpengaruh secara nyata mempengaruhi kesediaan atau kemauan membayar yaitu tingkat pendapatan dan kelompok masyarakat pengguna. Sedangkan kelima variabel yang tidak berpengaruh secara signifikan yaitu umur, tingkat pendidikan, penilaian masyarakat terhadap tingkat pelayanan, tingkat pengetahuan masyarakat mengenai iuran, dan jumlah pemakaian air.

Dari kedua penelitian tersebut dapat dilihat bahwa kesediaan atau kemauan membayar seseorang dipengaruhi oleh tingkat pendapatan

, tingkat pengetahuan dan biaya yang dikeluarkan setiap bulannya. Sedangkan yang tidak mempengaruhi yaitu jenis kelamin, usia, status pernikahan, tingkat pendidikan dan luas pekarangan.

\section{Kesimpulan}

Berdasarkan hasil dan pembahasan penelitian, maka dapat ditarik kesimpulan sebagai berikut:

1. Estimasi besarnya nilai WTP masyarakat terhadap peningkatan pelayanan PDAM di Jalan Danau Sentarum dan sekitarnya yaitu sebesar Rp 1.791,-- atau sebesar Rp 1.800,-. Nilai WTP ini meningkat Rp 200,- dari nilai yang telah ditetapkan oleh pemerintah Kota Pontianak pada tahun 2007 yaitu sebesar Rp 1.600,-.

2. Faktor-faktor dominan yang mempengaruhi kesediaan masyarakat dalam membayar iuran air untuk peningkatan pelayanan PDAM di Jalan Danau Sentarum dan sekitarnya yaitu tingkat pendapatan, tingkat pengetahuan dan pengeluaran rata-rata biaya pengeluaran rumah tangga setiap bulannya yang juga mempunyai hubungan yang positif.

\section{Ucapan Terima Kasih}

Terima kasih yang sebesar-besarnya kepada kedua orang tua saya, Bapak Sukarno dan Ibu Nur'Aini yang selalu mendo'akan, menyemangati, memberikan kasih sayang dan kekuatan untuk saya hingga dapat menyelesaikan kuliah S1 saya.

Kepada dosen-dosen pembimbing saya, Ibu Ir.Hj. RR. Endang Mulyani, MT dan Ibu Dr. Ir. Hj. Kartini, MT yang selalu mengarahkan dan membantu dalam mengerjakan tugas akhir ini. Serta kedua dosen penguji saya, Bapak Anwar Azazi, SE., DEA dan Bapak H. Kiki Prio Utomo, ST.,M.Sc terima kasih atas bimbingan dan ilmu kalian berikan, semoga dapat bermanfaat.

\section{Referensi}

Depkes RI (2009). Ilmu Kesehatan Masyarakat. Jakarta Blogspot.

Hanna Rambe (1984). Air dalam Neraca Tanah. Air Rekaman Lingkungan Hidup '84. Penyunting Bondan Winarno. Penerbit Sinar Harapan.

Simanjuntak, G.E. 2009. Analisis Willingness To Pay Masyarakat Terhadap Peningkatan Pelayanan Sistem Penyediaan Air Bersih Dengan WSLIC. Skripsi. Departemen Ekonomi Sumberdaya dan Lingkungan. Fakultas Ekonomi dan Manajemen. Institut pertanian Bogor.

Walpole, R. E. 1997. Pengantar Statistika Edisi ke-3. Jakarta. Gramedia Pustaka Utama.

Winarna ,S. 2003. Analisis Konsumsi Air Bersih Pelanggan Rumah Tangga Berdasarkan FaktorFaktor yang Mempengaruhinya. Tesis. Program Pasca Sarjana. Semarang . Universitas Diponegoro. 